\title{
Ethnobotanical Studies of Plants Used For Preservation of Plant Products in Ikere Ekiti, Ekiti State, Nigeria
}

\author{
Dr. Olanipekun M. K and Agbadaola O. J \\ Ekiti - State University, Ado- Ekiti, Nigeria. Department of Plant Science.
}

\begin{abstract}
The study aimed at the examination of botanicals used for preservation in Ikere-Ekiti, Ekiti-State. The study was carried out by interviewing the respondents using a well-structured, open-ended questionnaire and guided techniques. A total number of 25 species belonging to 18 families were collected and identified. There were more female respondents $(64 \%)$ than male (36\%). The respondents' indigenous technical knowledge revealed that most of the botanicals were single-components preparation while few involved the combination of more than one plants in a single usage.

Identified samples of the plant species used for preservation of plant produce were collected; their sources and method of application were defined. In addition, the folk medicinal values of the plants were also documented. Voucher specimens were deposited at the herbarium of Plant Science Department of Ekiti State University. However, some plants were found to be endangered, thus, strategies that could help in conserving them were proposed.
\end{abstract}

\section{Introduction}

Food crops and plant products need to be protected against biodegrading agents such as pest, fungi, bacteria and nematodes e.t.c. Preservation of plant products is important in order to increase the shelf life of the plants. Most plants and plant products are easily infected by pest, some easily break up and this leads to their destruction which makes them unfit for human use. Thus, the use of preservatives is highly imperative.

Plants like Capsicum fructesan, Vernona amygdalina and Azadirachta indica were promising examples of plants used for pest control and as a source of insecticide (NRC, 1992).

Preservatives are chemical or natural ingredients usually added to plant products to protect against decay or decomposition (Rosenthal et al, 1999) or to prevent spoilage (Pandey, 2002). The use of plants as preservatives over synthetic preservation is receiving more attention nowadays, this is because plants were found to be natural, cheaper, they are holistic in nature, easy to get and does not need the presence of skilled personnel before administration. (Rees and Banks, 2001; Olanipekun, 2011

Incidentally, in Nigeria, the preservative potentials of many plants have been known for a long time by the rural dwellers and the natural pesticides found embedded in plants have been used for pest control in rural areas. (Akinwumiet al, 2006)reported that the use of plant materials as preservatives shown that treated fish do not exhibit adverse evidence of smell or change in taste, texture or flavor.

Consequent on the above, it is therefore important to identify different plants used as preservatives and to propose sustainable strategies for the conservation of endangered species.

\section{Materials and Method}

The Study Area

The study was carried out in five villages in Ikere Local Government Area. The villages are Ogbese, Ayeye, Para, Oke-Eniju and Igbo-Oka in Ikere-Ekiti, Ekiti South Senatorial District, Ekiti-State. Ikere is an agricultural Centre and is located between Ado-Ekiti (the capital of Ekiti State) and Akure (the capital of Ondo State). The town enjoys tropical climate with two distinct seasons. These are the rainy season (April-October) and the dry season (October- March).Temperature ranges between $21^{\circ} \mathrm{C}$ and $28^{\circ} \mathrm{C}$ with high humidity. The land has favorable climatic conditions which makes the land enjoys luxuriant vegetation of timber. The inhabitants of this place practice agriculture, trading and rearing of livestock as the principal economic activities.

\section{Method}

A well-structured, open-ended questionnaire and guided dialogue techniques were used to interview farmers and the indigenous people of the areas. The questionnaire was designed based on the needed information on the various plants used as preservatives and interview was conducted in English Language, Yoruba Language and Ekiti dialect as situations demanded.

The respondents who chose to participate in the survey were asked to share their knowledge and experiences in the plants used in their communities as preservatives. In each community, twenty (20) individuals who had each maintained stable residence in the village for fifteen (15) years and above were selected and 
interviewed.Information were received and documented on the parts of the plants used and method of application. The plants were collected, identified and the voucher specimens were prepared and deposited at the Herbarium of Plant Science Department of Ekiti State University.

\section{Results and Discussion}

The result revealed a total of 25 plants species belonging to 18 families. They were identified and valued as been used as preservatives in the study area (Table1). Plantparts such as leaves, stem, fruits and bulbs were found used as preservatives. This confirms the assertion of Ramana (2008) that in India the leaves formed the bulk of the part of the plant used.

Table 2 revealed that respondents in the study areas were all familiar with the use of plants as preservatives. There were more female $(64 \%)$ than male $(36 \%)$. Most of the respondents were illiterate (70 people). The economic status of the respondents shows the rate at which the inhabitant accepted the use of plants. Thus, respondents of high status were 18, medium economic status ranked 32 while low economic status was 50 respondents. However, the result revealed that these features were not prerequisite to the consciousness of the respondents to the use of ethno-botanical plants.

Table1.List of identified botanicals used for preservation in Ikere-Ekiti

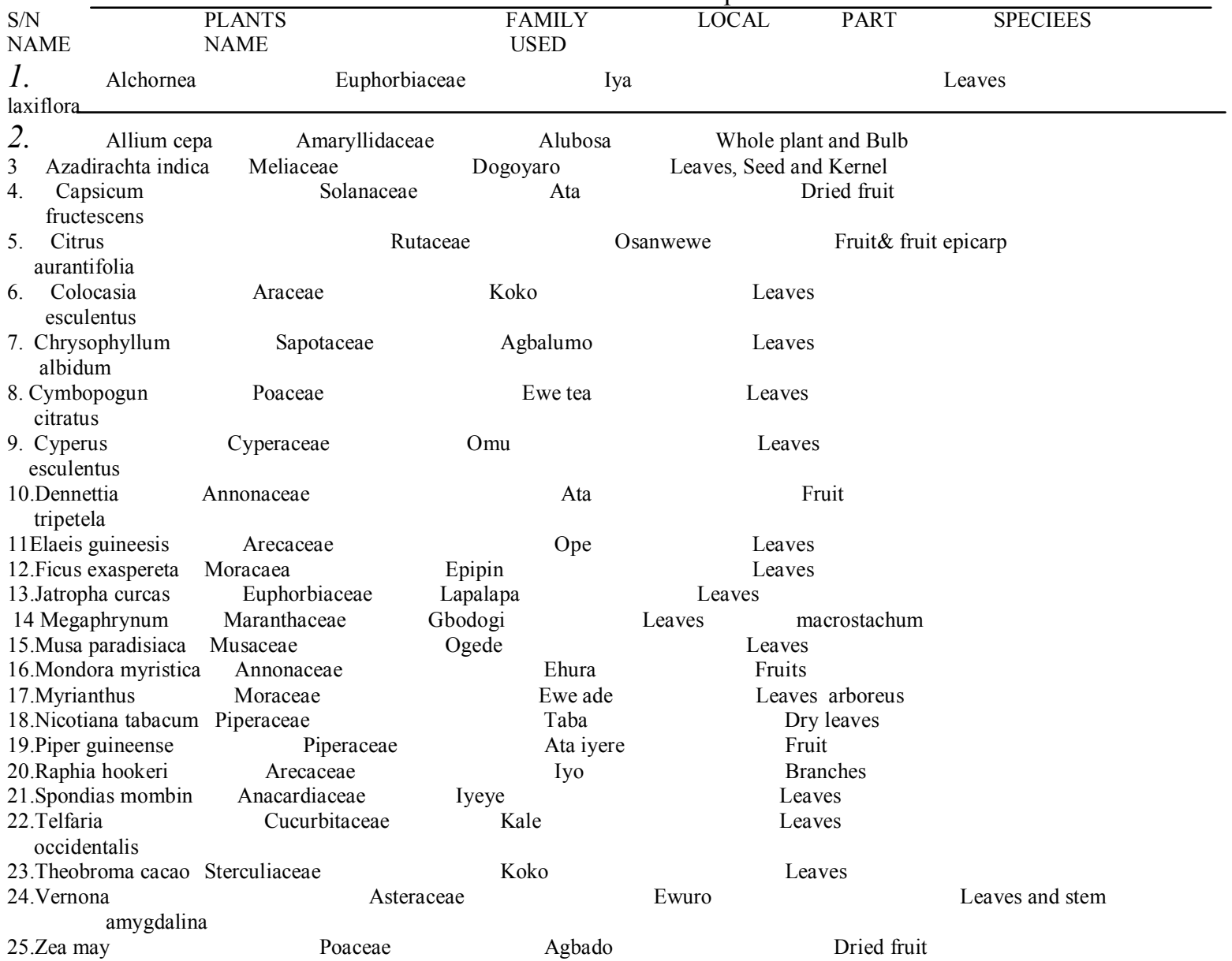

Table2.Ethnobotanical acceptability by the rural dwellers.

\begin{tabular}{|c|c|c|c|c|c|c|c|c|c|}
\hline \multirow[t]{2}{*}{ Features } & \multicolumn{2}{|c|}{ Description } & \multicolumn{7}{|c|}{ Proportion (\%) Respondents } \\
\hline & & & 1 & 2 & 3 & & 4 & 5 & Average Total (\%) \\
\hline & & & & $\mathrm{N}=20$ & $\mathrm{n}=20$ & & $\mathrm{n}=20$ & $\mathrm{n}=20$ & $\mathrm{n}=20$ \\
\hline \multirow[t]{2}{*}{$\overline{\operatorname{Sex}}$} & Male & & 5 & 7 & 10 & & 6 & 8 & 36 \\
\hline & Female & 15 & 13 & 10 & 4 & & 12 & 64 & \\
\hline \multirow[t]{2}{*}{ Age } & $15-50$ & & 10 & 8 & 6 & & 7 & 8 & 39 \\
\hline & $50-90$ & & 10 & 12 & 14 & 13 & 12 & 61 & \\
\hline \multirow{5}{*}{$\begin{array}{l}\text { Literacy Illiterate } \\
\text { status } \\
\text { Economic } \text { High } \\
\text { status }\end{array}$} & 15 & 13 & 16 & 12 & 14 & & 70 & & \\
\hline & Literate & 5 & 7 & 4 & 8 & & 6 & 30 & \\
\hline & & 4 & 2 & 6 & 2 & & 4 & 18 & \\
\hline & Medium & 8 & 6 & 6 & 6 & & 6 & 32 & \\
\hline & Low & & 8 & 12 & 8 & & 12 & 10 & 50 \\
\hline
\end{tabular}




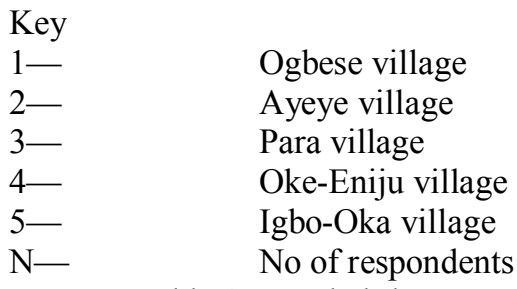

Table 3 revealed the respondents indigenous technical knowledge on the plants used as preservatives. Most of the botanicals were single-component preparation while few involved the combination of more than one plant in a single usage. The multiple components preparation includes the leaves of Megaphrynium macrostachum and Musa paradisiaca were used to preserve kolanuts while Theobroma cacao with Cyperus escuentus, were used to preserve locust beans from spoilage. Single-component preparation includes Alchornea laxiflorafor preservation of kolanut and Azadirachta indicafor the preservation of cowpea against weevil infestation among others. The usefulness of the botanicals as preservatives could be attributed to the present of bioactive components presents in them. This confirmed the assertion of (Stoll, 2000), Amusan and Okorie (2002) that plants is composed of bioactive agents or chemical substances that was found to be effective in the prevention of growth and development of Dermestes maculatus and Callosobrochus maculatus (Been weevil) and also aiding in repelling or killing some harmful insects. It was evident that the application of these various identified plants will protect the food produce from spoilage and unwholesomeness during storage and this will eventually accept usage by the customers.

Table 3. Respondent's indigenous technical knowledge on uses and method of application of plants used as preservatives in Ikere-Ekiti.

\begin{tabular}{llcl}
$\mathrm{S} / \mathrm{N}$ & Plant species & \multicolumn{1}{c}{ Uses } & Method of application \\
1. & Alchornea & For preservation of & Spread the leaves \\
laxiflora & \multicolumn{2}{c}{ kolanut against insect } & inside a basket then
\end{tabular}

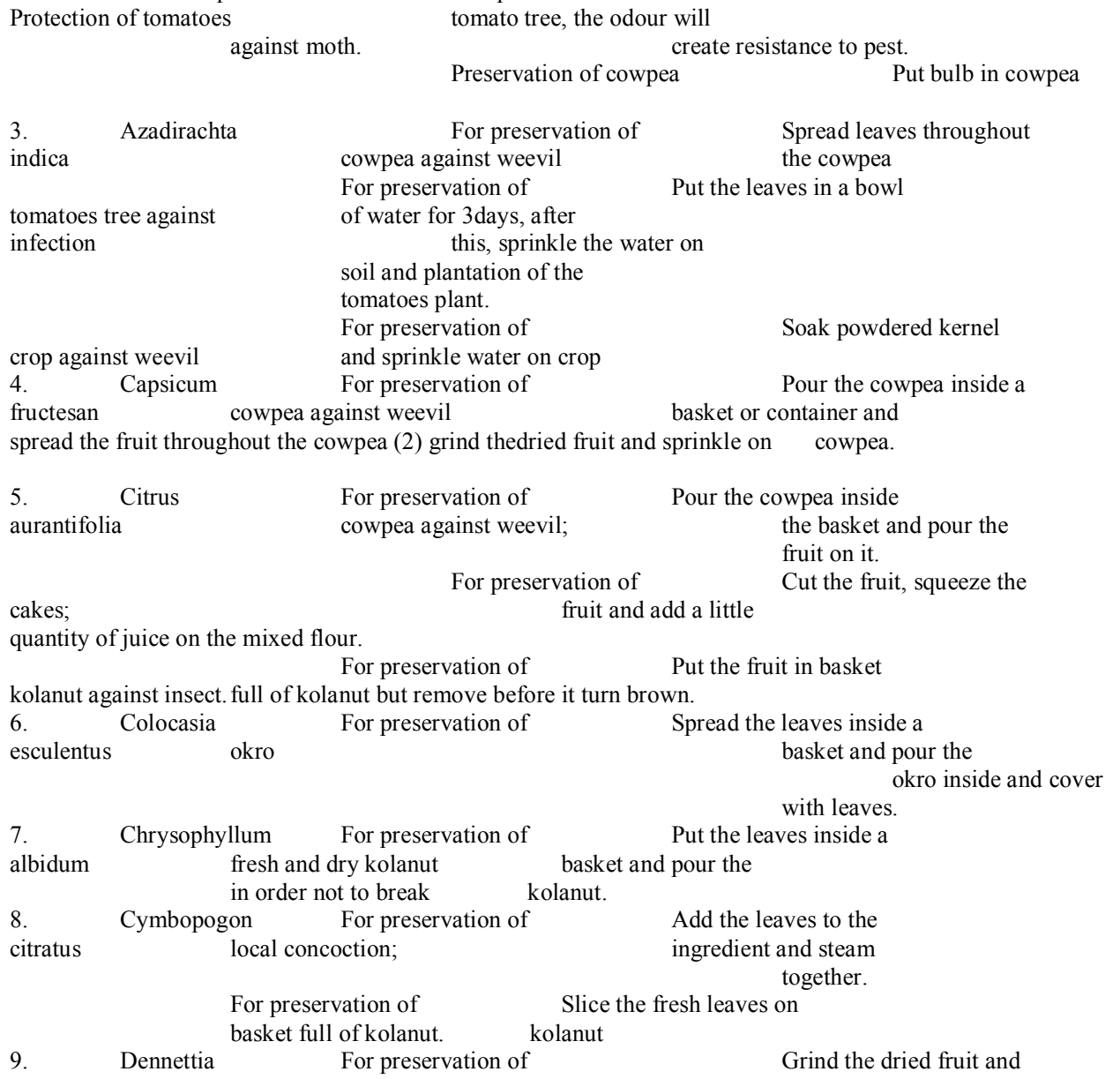




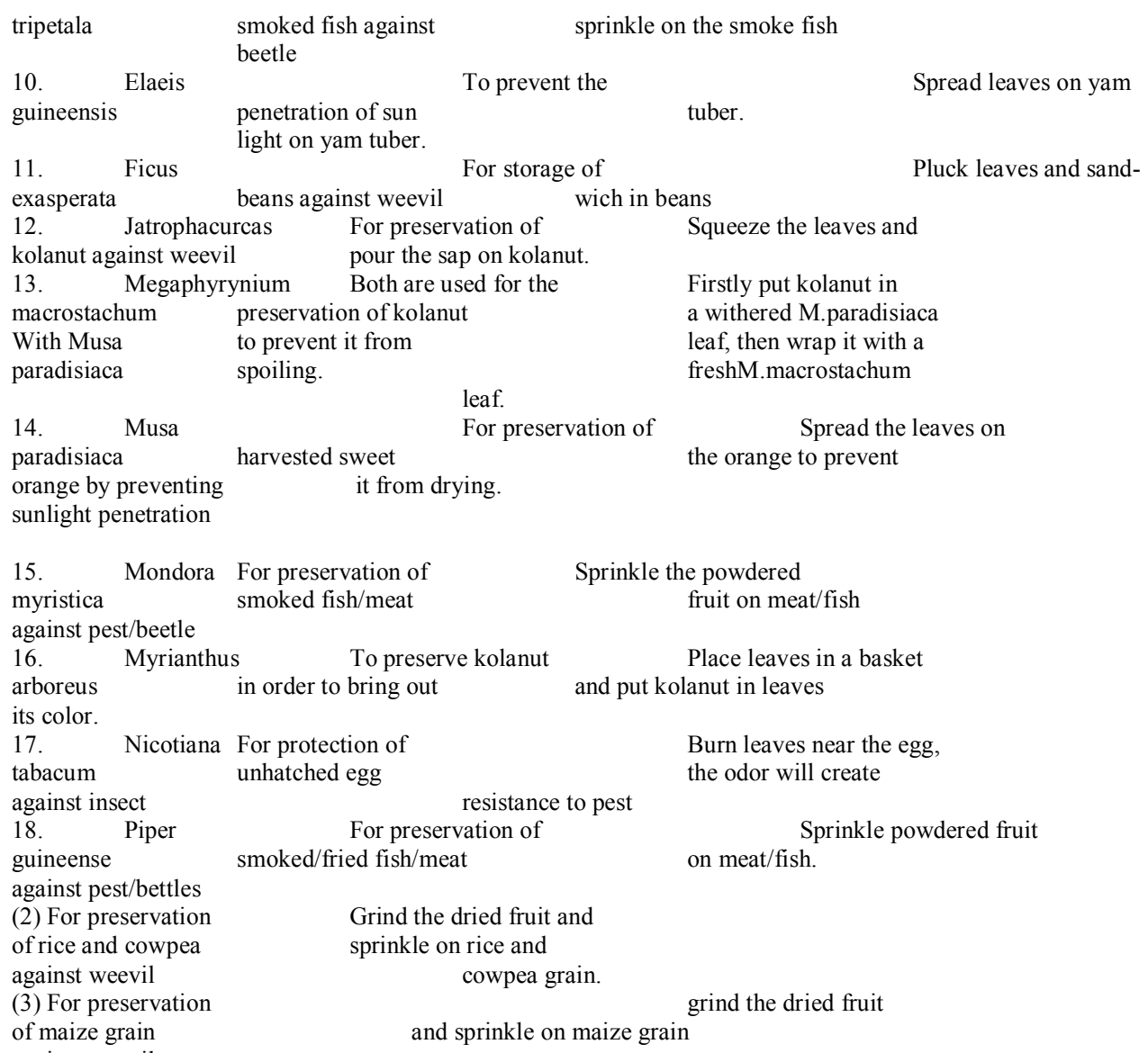

\section{Conclusion and Recommendations}

The result obtained in this study shown the potential of botanicals in preserving the quality and quantity of food and plants produce. Hence, current knowledge and new findings about this promising plant products used for preservation needs to be transformed into practical applications which are acceptable by the users. Neglecting this can leads to a negative setback from the farmers which result in a decreasing interest to the use of natural preservatives. 
From the result gotten from this study, the following recommendations should be considered:

1. Government should make funds available for the researchers so as to encourage them in their field.

2. Seminars should be organized by government officials so as to educate people on the importance and efficacy of these botanicals.

3. Enlightenment on the dangers of extinction of most of these species should be made.

4. There is need to revive and encourage the traditional practices of conserving forest such as the dedication of forest to deities.

\section{References}

[1]. Akinwumi, F.O; E.A. Fasakin and C.O Adedire (2006): Progeny inhibiting effects of four plant products against the leather beetle and copra beetle on smoked African mud fish. Journal Bio.Sci ;6;1023-1028.

[2]. Amusan, A.A.S and T.G. Okorie (2002). The use of Piper guineense fruit oil as protectant of dried fish against Dermestes maculates (DEGEER) infestation. Global Journal of Pure Apllied Sci.,8;197-201.

[3]. National research council (NRC) (1992): Neem A tree of solving global problem by national academic press.

[4]. Ogunnika (2007): Medicinal plants: A potential agroforestry component in Nigeria. In proceeding of the Humboldt Kellog/3 Annual conference of school of Agric and Agric Tech Sch of Agric Tech (pp 2-7).Akure, Ondo State, Nigeria.

[5]. Pandey (2002): Effectiveness of some indigenous plants products against insect pest of cruciferous vegetables. Ent. 69 (2); $129-32$.

[6]. Rees and Banks (2001): Alternative methods for the control of stored product insect pest. A bibliographic Database.

[7]. Rosenthal, Gerald A and M. Berenbaum (1999): Herbivores, their interaction with secondary plant metabolite. Academy press.

[8]. Stoll G. (2000): National crop protection in the tropics $2^{\text {nd }}$ Edn, MangrafVerlagWeikersheim (2000): p.376.

[9]. United Nation Forum on Forest UNFF (2002), 'Forest ant the World Summit'

[10]. Wilson (1992) The Diversity of Life. Harvard University Press, ISBN 0-674- 21298-3. 